\title{
EFFECT OF POLYMERIC BLEND ON EX-VIVO PERMEATION STUDIES OF ACECLOFENAC LOADED FILM FORMING GEL
}

\author{
HIMANI BAJAJ ${ }^{1,3}$, VINOD SINGH ${ }^{2}$, RANJIT SINGH ${ }^{3}$, TIRATH KUMAR ${ }^{1 *}$
}

1Department of Pharmaceutical Sciences, Bhimtal Campus, Kumaun University, Nainital, ${ }^{2}$ Department of Pharmaceutical Sciences, Gurukul Kangri Vishwavidyalaya, Haridwar, ${ }^{3}$ AVIPS, Shobhit University, Gangoh, Saharanpur

*Email: kambojt2@yahoo.co.in

Received: 01 Mar 2021, Revised and Accepted: 22 Apr 2021

\section{ABSTRACT}

Objective: To date, film-forming systems have been intensively investigated for transdermal drug delivery. Film-forming systems offers various advantages compared over conventional transdermal drug delivery systems. The objective of the present study was to study the effect of polymeric blend on ex-vivo permeation studies of topical film-forming gel of aceclofenac.

Methods: Film-forming gels were prepared by using Hydroxypropyl methylcellulose and Eudragit polymeric blend in varied concentrations, polyethylene glycol 400 as plasticizer, ethanol as solvent and tween 80 as a penetration enhancer. The prepared film-forming gels were evaluated and the influence of the concentration and ratio of polymeric blends used plasticizer and ethanol were investigated.

Results: All the prepared film-forming gels showed satisfactory properties regarding homogeneity, compatibility, viscosity and pH value. Variation in the concentration of polymers showed a variable effect on drug permeation rate from film-forming gels. Almost, all formulations permeated up to $80 \%$ of drug in $12 \mathrm{~h}$ and formulation F1 showed a maximum release about $97.54 \%$ in $12 \mathrm{~h}$.

Conclusion: Film-forming gels of aceclofenac with sustained-release profile were successfully developed and may provide a promising effective formulation which may improve patient compliance.

Keywords: Film-forming gel, Aceclofenac, Polymer, Transdermal

(c) 2021 The Authors. Published by Innovare Academic Sciences Pvt Ltd. This is an open access article under the CC BY license (https://creativecommons.org/licenses/by/4.0/) DOI: https://dx.doi.org/10.22159/ijap.2021v13i4.41257. Journal homepage: https://innovareacademics.in/journals/index.php/ijap

\section{INTRODUCTION}

Rheumatoid arthritis is an autoimmune disease in which there is joint inflammation, synovial proliferation and destruction of articular cartilage. It is a chronic progressive, crippling disorder [1]. Arthritis of joints involves inflammation of the synovial membrane, Joints become swollen, tender and warm, stiffness limits their movement and found in small joints of hands, feet, cervical spine. Usually, this disease occurs at the joints, where applied medicament is wiped off, due to clothes or any other reason. Thus, there is a need to develop to novel drug delivery system which is in a gel form in a tube or container, but when applied to skin surface converts or transform into a film. Initially, gels provide a drug release and after transformation into film prolonged drug release was maintained. This concept is helpful for patients suffering from Rheumatoid Arthritis where sustained action is required as the frequency of administration is more [2].

Non-Steroidal Anti-inflammatory drugs (NSAIDS) are used first, which provide symptomatic relief (pain, swelling, morning stiffness, immobility). Non-steroidal anti-inflammatory drugs such as aceclofenac have been widely used in the treatment of rheumatoid arthritis, osteoarthritis and musculoskeletal disorders. In oral administration of Non-Steroidal Anti-Inflammatory Drugs, tablets and capsules led to peptic ulceration anorexia. Other side effects such as headache, giddiness, and blurring of vision may take place [3].

To date, film-forming systems (FFS) have been intensively investigated for transdermal drug delivery [4]. The FFS are the semisolid system containing film-forming agents along with the drug that forms film in-situ after solvent evaporation. They either act as a sustained drug release polymeric matrix or as a solvent film that can rapidly absorb within the skin. Compared to conventional topical/transdermal drug delivery systems, FFS offers various benefits, such as non-greasy, transparency, resistant to wipe off, longer residence at the site of application, low skin irritation, ease of dosage adjustment and greater patient compliance [5]. The studies conducted to date have shown promising results, however, further studies are needed to establish FFS as an effective drug delivery carrier for transdermal application. In the present investigation, film-forming systems were developed and evaluated for effective transdermal delivery of Aceclofenac (ACF).

\section{MATERIALS AND METHODS}

\section{Materials}

Aceclofenac was gifted from Shiva Biogenetic Pharmaceuticals Pvt. Ltd., Solan India. Eudragit RL 100 was procured from Evonik, Germany, India. Polyethylene Glycol (PEG-400) and Hydroxypropyl Methyl Cellulose (HPMC) were purchased from SD fine chemicals Ltd., India. Ethanol (99\% purity) was purchased from Merck, Germany. All other chemicals used in the experiments were of analytical grade.

\section{Methods}

\section{Development of film-forming system}

The polymeric solution of eudragit was prepared by dispersion method using ethanol as solvent. HPMC was sprinkled over $10 \mathrm{ml}$ of ethanol separately. Both solutions were allowed to swell for $24 \mathrm{~h}$ to produce clear solutions. The polymeric solutions were mixed properly with continuous stirring. The ACF drug was dissolved in a specified quantity of ethanol. Solvent ethanol is used as it is capable of dissolving the drug and is rapidly evaporated after topical evaporation leaving a film on the skin. The drug and polymeric dispersion were mixed properly with continuous stirring. Finally, tween 80, Polyethylene glycol was added to it and volume was made up to the mark using ethanol and stirring it until a smooth gel is obtained. The speed of stirrer was maintained in the range of 500 $1000 \mathrm{rpm}$. During the formulation, development care should be taken to avoid air bubbles formation [20]. The formulation chart is shown in table 1. 
Table 1: Formulation design of aceclofenac-loaded film-forming gel

\begin{tabular}{|c|c|c|c|c|c|c|}
\hline Formulation code & ACF (\%) & HPMC (\%) & Eudragit RL100 (\%) & PEG400 (\%) & Tween 80 (\%) & Ethanol \\
\hline F1 & 1 & 1 & 0.4 & 3 & 0.5 & q. $s$ \\
\hline $\mathrm{F} 2$ & 1 & 2 & 0.4 & 3 & 0.5 & q. $s$ \\
\hline F3 & 1 & 3 & 0.4 & 3 & 0.5 & q. $s$ \\
\hline F4 & 1 & 1 & 0.6 & 3 & 0.5 & q. $s$ \\
\hline F5 & 1 & 2 & 0.6 & 3 & 0.5 & q. $s$ \\
\hline F6 & 1 & 3 & 0.6 & 3 & 0.5 & q. $s$ \\
\hline F7 & 1 & 1 & 0.8 & 3 & 0.5 & q. $s$ \\
\hline F8 & 1 & 2 & 0.8 & 3 & 0.5 & q. $s$ \\
\hline F9 & 1 & 3 & 0.8 & 3 & 0.5 & q. $s$ \\
\hline
\end{tabular}

\section{Physicochemical evaluation \\ Compatibility studies}

Drug-excipient interaction was evaluated using FT-IR spectroscopy [4]. IR spectrum of the drug and its combinations with other excipients were recorded from the Potassium bromide $(\mathrm{KBr})$ dispersion method using AX-1 spectrophotometer (Perkin Elmer, USA). The film-forming gel samples was dried and crushed so as it can be easily combined with $\mathrm{KBr}$ (1:1) were recorded over the range of 400 to $4000 \mathrm{~cm}^{-1}$ with the resolution of $4 \mathrm{~cm}^{-1}$.

\section{pH measurements}

The developed films were kept in the purified water $(5 \mathrm{ml})$ for $2 \mathrm{hr}$ at room temperature with continuous stirring. The $\mathrm{pH}$ of the solution was measured by keeping the electrode in contact with the surface of the film under a swelling state [6]. The experiment was carried out in triplicate $(\mathrm{n}=3)$.

\section{Rheological studies}

The viscosity and the torque of the developed gel formulations were measured using a digital Brookfield viscometer LVDV II+model with S 64 spindle [7]. The measurement was performed at a controlled temperature of $30 \pm 2{ }^{\circ} \mathrm{C}$. About $0.5 \mathrm{gm}$ of the developed formulation was used for the measurements. The viscosity and torque were determined at 20,50 and $100 \mathrm{rpm}$. The experiment was carried out in triplicate $(n=3)$.

\section{Drug content}

The gel formulation of $1 \mathrm{gm}$ was taken in a volumetric flask filled with $100 \mathrm{ml}$ of PBS (pH 6.8). The volumetric flask filled with drugloaded gel along with PBS stirred for $2 \mathrm{hr}$ using a mechanical stirrer in order to dissolve the drug from the gel into the solvent. The solution was filtered through Whatman filter paper. The absorbance was recorded by UV Vis spectrophotometer at $275 \mathrm{~nm}$ after suitable dilutions [8].

\section{Homogeneity}

The developed gel formulations were placed on the petri dish and allowed to set into it. These formulations were evaluated for their appearance and any possible aggregates via visual inspection.

\section{Ex-vivo skin permeation study of film-forming gel}

$E x$-vivo skin permeation study was carried out as per the method described in the literature [9]. The experimental procedures and protocols were reviewed and approved by the Institutional Animal Ethical Committee (IAEC) [CPCSEA/IAEC/SBS/2017-18/009] Sardar Bhagwan Singh Post Graduate Institute of Biomedical Sciences and Research, Balawala, Dehradun. The animals were housed in standard polypropylene cages and maintained under controlled room temperature $\left(22 \pm 2{ }^{\circ} \mathrm{C}\right)$ and relative humidity $(55 \pm 5 \%)$ with 12:12 hour light and dark cycle. The animals were provided with commercially available rat normal pellet diet and water ad libitum. A section of the young rat skin $(3 \times 3 \mathrm{~mm})$ from the abdominal region of the rat was carefully excised after animal sacrifice. The hairs on the skin were removed with the help of scissors and any undesirable matter was wiped-out with the help of cotton. The cleaned skin was then washed with saline before the experiment. Ex-vivo skin permeation of ACF-loaded film forming gels F1-F9 was investigated at predetermined time points $0,0.5,1,2,4,6,8,10$ and $12 \mathrm{~h}$ using
Franz-diffusion cell. The abdominal skin was washed with PBS $(\mathrm{pH}$ 6.8) and mounted over the diffusion cell. About $1 \mathrm{gm}$ of the gel was placed on the donor compartment and covered with aluminium foil to prevent drying out of the gel. The temperature of the cell was maintained at $37 \pm 5{ }^{\circ} \mathrm{C}$ and the medium was by magnetic stirrer at $100 \mathrm{rpm}[10]$.

Sample $(2 \mathrm{ml})$ were collected from the receptor compartment at a predetermined time interval and then immediately analyzed spectrophotometrically at $275 \mathrm{~nm}$ against a blank prepared with the permeated formulation without the drug. At each sampling time point, the medium of the receptor compartment was replaced by the equal volume of fresh medium. The experiment was carried out in triplicate $(n=3)$. Graph was plotted between the cumulative amount of drug permeated in receptor compartment versus time.[21].

\section{RESULTS AND DISCUSSION}

\section{Formulation development}

The ACF-loaded film-forming gels (F1-F9) were developed using variable composition of gelling and film-forming agents (table I). To enhance the solubility of the drug and its penetration through the skin, PEG and Tween 80 were added in the formulation. The developed formulations were evaluated for various physicochemical parameters.

\section{Compatibility studies}

FTIR spectrum of the drug ACF was recorded over the range of 400 to $4000 \mathrm{~cm}^{-1}$ with the resolution of $4 \mathrm{~cm}^{-1}$ (fig. 1). The peak at 3318 $\mathrm{cm}^{-1}$ represents-NH Stretching related to broad secondary amine and carboxylic acid (hydroxyl) band in ACF. Peak at $\left(1716.8 \mathrm{~cm}^{-1}\right)$ represents- $\mathrm{C}=0$ Stretching of ketone band. Peak at $\left(1589.5 \mathrm{~cm}^{-1}\right)$ represents the $\mathrm{C}=\mathrm{C}$ bending of the aromatic group. Peak at $\left(1500 \mathrm{~cm}^{-}\right.$ $\left.{ }^{1}\right)$ represents $C-C$ bending of the aromatic group. Peak at (1480.61 $\mathrm{cm}^{-1}$ ) represents the $\mathrm{C}=\mathrm{C}$ bending of the aromatic group. Peak at $\left(1178.86 \mathrm{~cm}^{-1}\right)$ represents $\mathrm{C}-0$ stretching of carboxylic acid in ACF.

FTIR spectrum of the drug ACF and HPMC was recorded over the range of 400 to $4000 \mathrm{~cm}^{-1}$ with a resolution of $4 \mathrm{~cm}^{-1}$ (fig. 2). The mixture showed the characteristic peaks of ACF and HPMC. The broad peak $\left(3371.62 \mathrm{~cm}^{-1}\right)$ represents-NH Stretching related to broad secondary amine and carboxylic acid (hydroxyl) band in ACF. Peak at $\left(1067.58 \mathrm{~cm}^{-1}\right)$ represents-C-O stretching which is characteristic of glucose ring present in HPMC. Peak at $\left(1642 \mathrm{~cm}^{-1}\right)$ represents- $\mathrm{C}=0$ stretching of carboxylic in ACF. Peak at $\left(1387 \mathrm{~cm}^{-1}\right)$ represents $\mathrm{C}-\mathrm{OH}$ bending in $\mathrm{ACF}$ and peak at $\left(1216 \mathrm{~cm}^{-1}\right)$ depicts $\mathrm{C}-\mathrm{N}$ stretching. As per the FTIR spectrum of ACF and HPMC, the mixture showed compatibility and their suitability for the formulation development.

FTIR spectrum of the drug ACF and Eudragit was recorded over the range of 400 to $4000 \mathrm{~cm}^{-1}$ with the resolution of $4 \mathrm{~cm}^{-1}$ (fig. 3). The mixture showed the characteristic peaks of ACF and eudragit. The broad peak $\left(3368 \mathrm{~cm}^{-1}\right)$ represents-NH Stretching related to broad secondary amine and carboxylic acid (hydroxyl) band in ACF. Peak at $\left(2923 \mathrm{~cm}^{-1}\right)$ represents-CH stretching of alkane group present in eudragit. Peak at $\left(1644.37 \mathrm{~cm}^{-1}\right)$ represents $-\mathrm{C}=0$ stretching of carboxylic in ACF. Peak at $\left(1387 \mathrm{~cm}^{-1}\right)$ represents $\mathrm{C}-\mathrm{OH}$ bending in $\mathrm{ACF}$ and peak at $\left(770 \mathrm{~cm}^{-1}\right)$ depicts $\mathrm{C}$-Cl stretching. As per the FTIR spectrum of ACF and eudragit, the mixture showed compatibility and their suitability for the formulation development. 


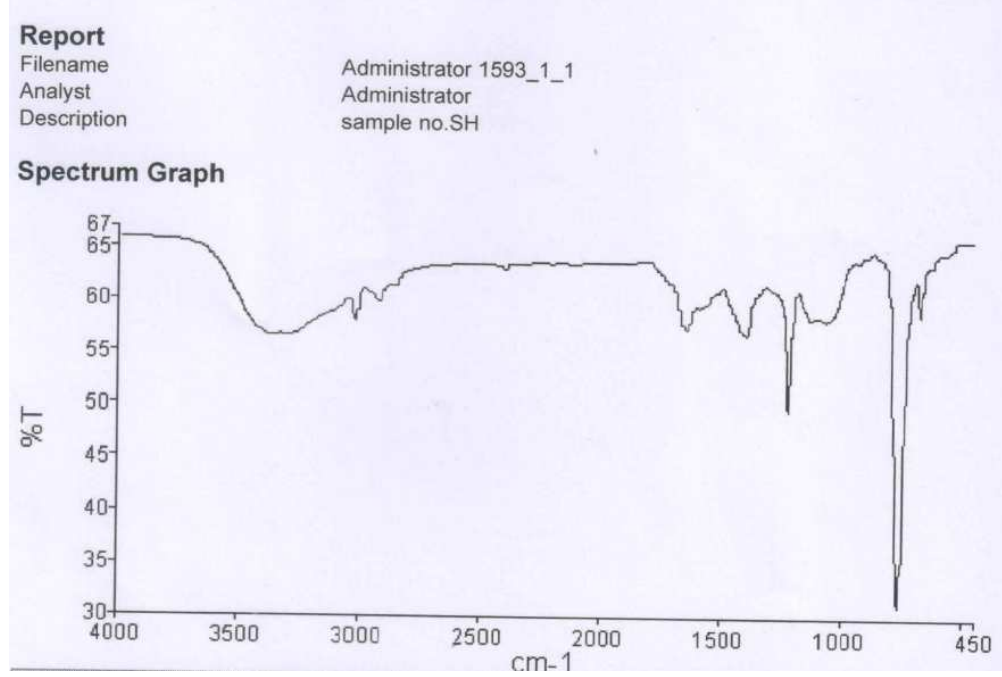

Fig. 1: FTIR spectrum of ACF recorded over the range of 400 to $4000 \mathrm{~cm}^{-1}$ with the resolution of $4 \mathrm{~cm}^{-1}$

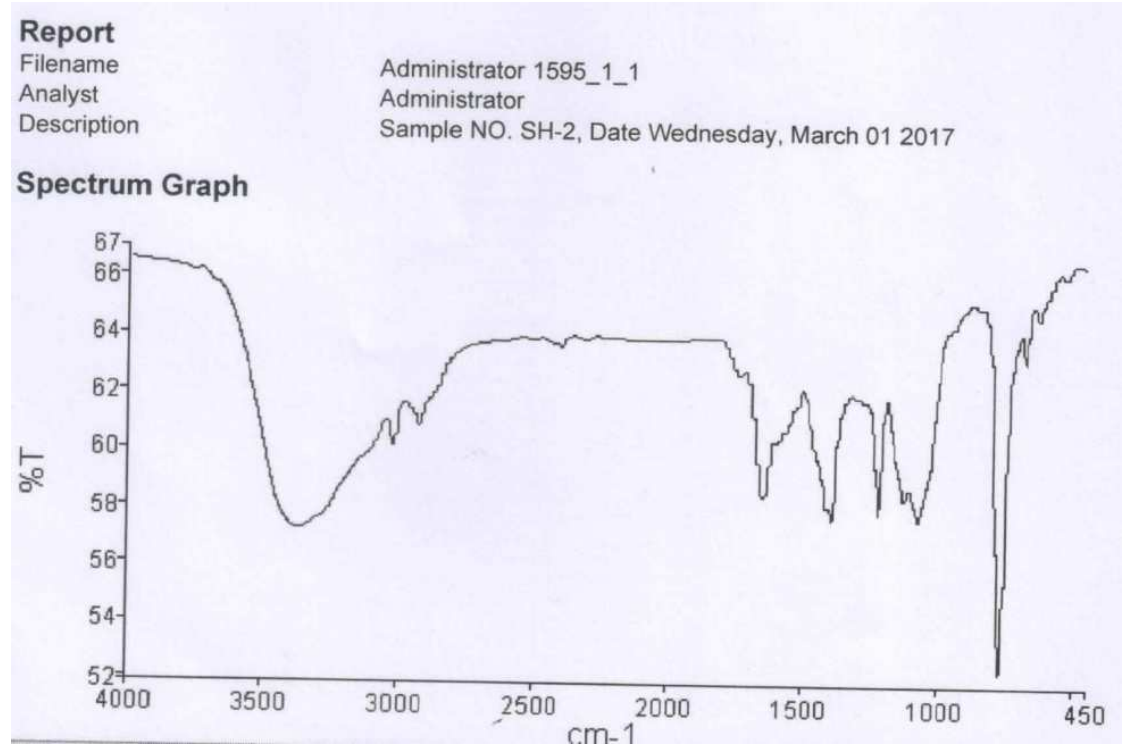

Fig. 2: FTIR spectrum of ACF+HPMC recorded over the range of 400 to $4000 \mathrm{~cm}^{-1}$ with the resolution of $4 \mathrm{~cm}^{-1}$

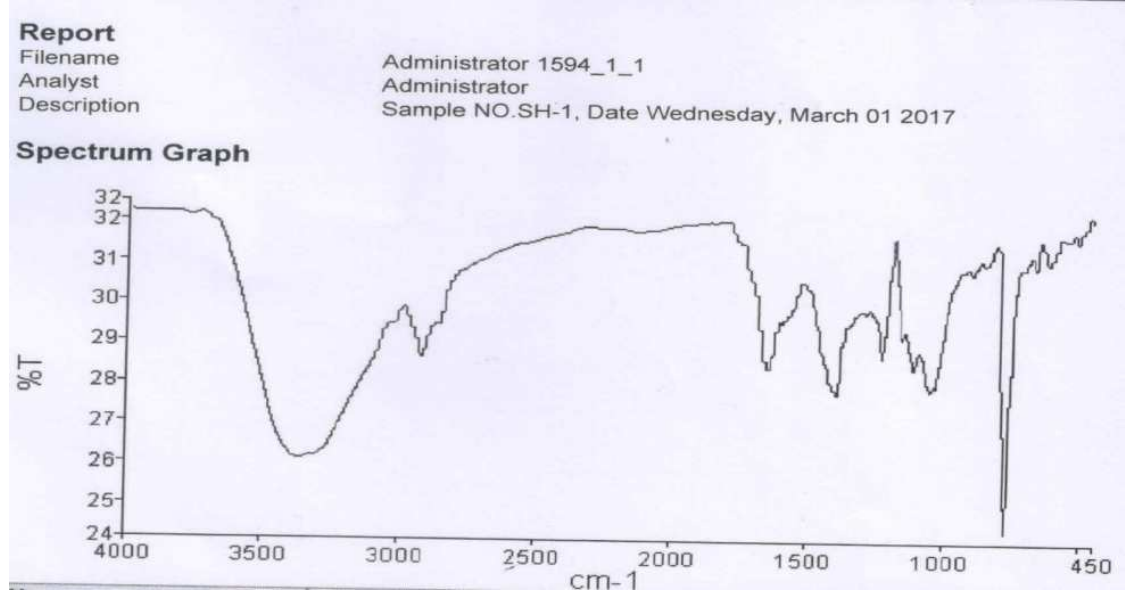

Fig. 3: FTIR spectrum of ACF+Eudragit recorded over the range of 400 to $4000 \mathrm{~cm}^{-1}$ with the resolution of $4 \mathrm{~cm}^{-1}$ 


\section{Physical appearance}

Initially, the gel formulation was transparent in nature after application. However, it rapidly transformed into opaque with film formation. When the film was completely dried, it transformed from opaque to transparent.

\section{pH measurement}

The pH of the gels for transdermal applications should lie within the limits of normal skin $\mathrm{pH}$ of 4.5-6.8. The $\mathrm{pH}$ range deviated from this range may cause immunological responses like redness, burning and itching of the skin. The prepared film-forming gel formulations F1F9 have a pH range of $5.4 \pm 0.18$ to $6.3 \pm 0.08$ which is within the $\mathrm{pH}$ range desired for the skin [11].

\section{Viscosity}

The viscosity (cps) and torque (\%) of the developed formulations (F1F3) was evaluated at 20,50 and $100 \mathrm{rpm}$ using a digital Brookfield viscometer LVDV II+model with S 64 spindle (table 2). Formulations F3, F6 and F9 were not evaluated because they were out of the range of spindle S 64 maximum capacity of detection (as the spindles of higher detection limits were unavailable). The formulation F1 had the least viscosity whereas F8 being the most vicious, this increase in viscosity can be attributed to the increase in the polymer concentration of HPMC as we move down the developed formulations within the group. In addition, it was revealed that there was a decrease in viscosity with an increase in RPM which represents the resistive force offered by the gel to the rotation of the spindle [12].

Table 2: The viscosity of the film forming systems (mean \pm SD)

\begin{tabular}{|c|c|c|c|c|c|c|c|c|}
\hline \multicolumn{9}{|c|}{ Viscosity studies } \\
\hline \multirow{2}{*}{$\begin{array}{l}\text { Formulation } \\
\text { code }\end{array}$} & \multirow{2}{*}{$\begin{array}{l}\text { RPM } 10 \\
\text { \% Torque } \\
\end{array}$} & \multirow{2}{*}{$\begin{array}{l}\text { Viscosity } \\
\text { (cps) }\end{array}$} & \multirow{2}{*}{$\begin{array}{l}\text { RPM } 20 \\
\text { \% Torque } \\
\end{array}$} & \multirow{2}{*}{$\begin{array}{l}\text { Viscosity } \\
\text { (cps) }\end{array}$} & \multirow{2}{*}{$\begin{array}{l}\text { RPM } 50 \\
\% \text { Torque }\end{array}$} & \multirow{2}{*}{$\begin{array}{l}\text { Viscosity } \\
\text { (cps) }\end{array}$} & \multirow{2}{*}{$\begin{array}{l}\text { RPM } 100 \\
\text { \% Torque }\end{array}$} & \multirow{2}{*}{$\begin{array}{l}\text { Viscosity } \\
\text { (cps) }\end{array}$} \\
\hline & & & & & & & & \\
\hline F1 & 0.6 & $349.9 \pm 0.03$ & 1.2 & $349.9 \pm 0.05$ & 2.4 & $277.9 \pm 0.04$ & 4.1 & $235.9 \pm 0.05$ \\
\hline $\mathrm{F} 2$ & 13.7 & $8118 \pm 0.05$ & 18.5 & $5449 \pm 0.04$ & 28.2 & $2183 \pm 0.04$ & 39.7 & $2281 \pm 0.04$ \\
\hline $\mathrm{F} 4$ & 0.6 & $349.9 \pm 0.02$ & 1.2 & $349.9 \pm 0.04$ & 2.6 & $311.9 \pm 0.02$ & 4.4 & $253.9 \pm 0.03$ \\
\hline F5 & 26.2 & $13217 \pm 0.03$ & 27.8 & $8238 \pm 0.02$ & 35.2 & $4189 \pm 0.04$ & 40 & $2299 \pm 0.02$ \\
\hline F7 & 0.7 & $409.9 \pm 0.04$ & 1.1 & $319.9 \pm 0.03$ & 1.9 & $218 \pm 0.05$ & 37.5 & $158 \pm 0.05$ \\
\hline F8 & 26.1 & $13961 \pm 0.02$ & 31.9 & $9438 \pm 0.02$ & 37.5 & $4399 \pm 0.03$ & 41 & $2359 \pm 0.04$ \\
\hline
\end{tabular}

Note: All data are presented as mean value \pm SD and $n=3$

Table 3: Drug content of the film-forming systems

\begin{tabular}{|c|c|c|c|c|c|c|c|c|c|}
\hline \multicolumn{10}{|c|}{ Drug content of formulations } \\
\hline Formulation no. & F1 & F2 & F3 & F4 & F5 & F6 & F7 & F8 & F9 \\
\hline Drug content (\%) & $\begin{array}{l}98.83 \\
\pm 0.305\end{array}$ & $\begin{array}{l}99.75 \\
\pm 0.532\end{array}$ & $\begin{array}{l}99.53 \\
\pm 0.550\end{array}$ & $\begin{array}{l}98.76 \\
\pm 0.321\end{array}$ & $\begin{array}{l}99.81 \\
\pm 1.044\end{array}$ & $\begin{array}{l}99.52 \\
\pm 0.251\end{array}$ & $\begin{array}{l}98.85 \\
\pm 0.150\end{array}$ & $\begin{array}{l}99.11 \\
\pm 0.563\end{array}$ & $\begin{array}{l}99.64 \\
\pm 0.571\end{array}$ \\
\hline
\end{tabular}

Note: All data are presented as mean value $\pm \mathrm{SD}$ and $n=3$

\section{Drug content}

The drug content of the developed formulations was found in the range of $98.76 \pm 0.321-99.83 \%$ (table 3 ).

\section{Homogeneity}

The developed formulations in a gel form were evaluated for their homogeneity. All the developed film-forming systems (F1-F9) were found homogeneous without any grittiness. This ensures a smooth application of the formulation which avoids any possible abrasion on the skin [13].

\section{Ex-vivo skin permeation study}

The developed formulations were evaluated for their ability to permeate the drug efficiently through the skin in a sustained manner. In addition to the control release property, the eudragit also acts as a film-forming agent for topical formulations. In addition, Tween 80 increases the solubility of the hydrophobic drug and enhances the permeation of the drug through the skin. It can be easily seen from the results that came from ex-vivo permeation studies that with an increase in the polymer concentration the release increases.

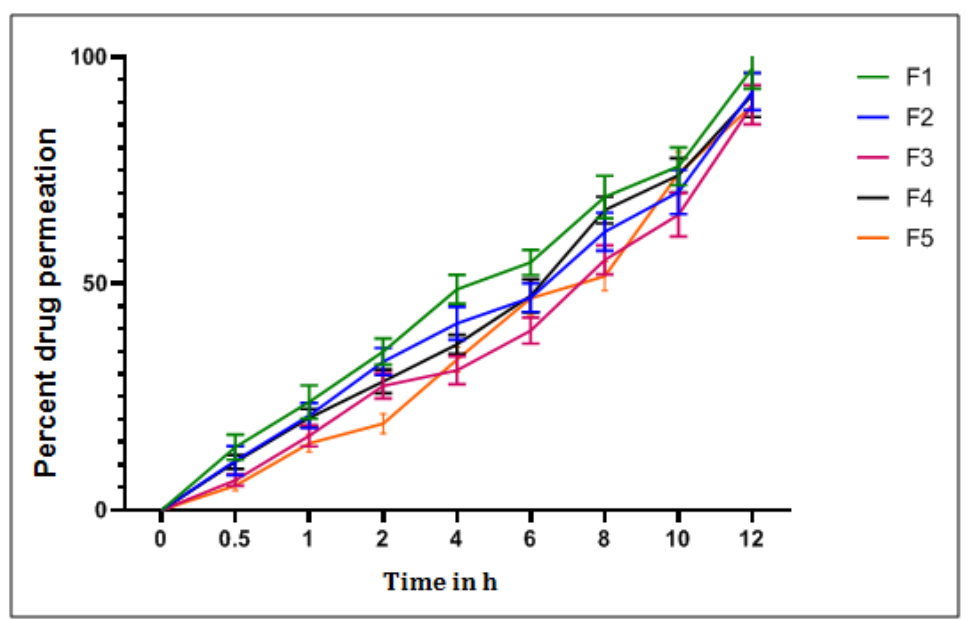

Fig. 4: Percent drug permeation of film-forming systems (F1-F5) (mean \pm SD and n=3) 


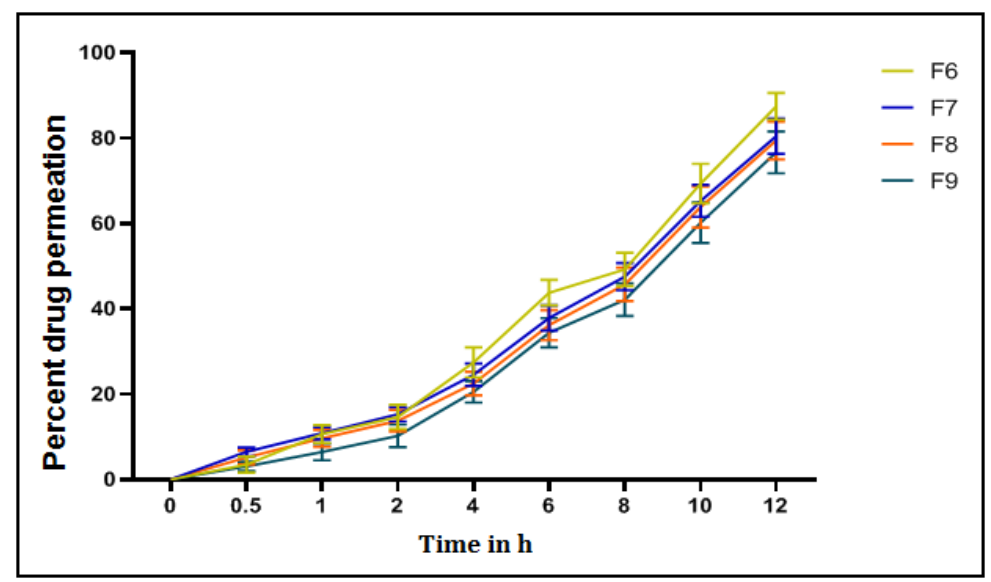

Fig. 5: Percent drug permeation of film-forming systems (F6-F9) (mean \pm SD and n=3)

The ex-vivo permeation study showed that the developed formulations showed a sustained release effect depending upon the concentration of the polymers $[16,17]$. It can be seen from the permeation study that with an increase in the concentration of HPMC and Eudragit, the loaded ACF releases from the polymer matrix at the slower rate as shown in fig. 4 and fig. 5. The formulations F7, F8 and F9, due to high polymeric concentration showed large sustained drug release effect compared to the formulations F1-F6.

\section{CONCLUSION}

Diseases, such as rheumatoid arthritis usually occurs in joints where there is a great possibility exists that the applied dosage form can easily wipe off following its topical application. Therefore, we developed film-forming systems that have an ability to be there for a longer time period. The present investigation showed that the developed ACF-loaded film-forming gels have acceptable physicochemical properties for the topical application. After the topical application, the gel form converts into a thin film which releases the drug in a sustained manner. The FTIR studies showed compatibility between the drug and the excipients and their suitability for the formulation development. Ex vivo permeation studies showed the sustained release properties of the developed formulation. To conclude, film-forming systems have a great potential for the management of various diseases. However, a further in-depth investigation is warranted to transform this formulation into a successfully marketed product for human application.

\section{ACKNOWLEDGEMENT}

The authors profoundly acknowledge Sardar Bhagwan Singh Post Graduate Institute of Biomedical Sciences and Research, Balawala, Dehradun, India for providing the animal facilities and Shiva Biogenetic pharmaceuticals Pvt. Ltd., Solan India for providing gift sample of aceclofenac.

\section{FUNDING}

Nil

\section{AUTHORS CONTRIBUTIONS}

All the authors have contributed equally.

\section{CONFLICTS OF INTERESTS}

Declared none

\section{REFERENCES}

1. Baljit K, Qadrie ZL, Amit B, Gautam SP. A never-ending story of rheumatoid arthritis. Int J Pharm Pharm Sci 2020;12:10-7.

2. Ranade S, Bajaj A, Londhe V, Kao D, Babul N. Fabrication of polymeric film forming topical gels. Int J Pharm Sci Rev Res 2014;26:306-13.
3. Frederiksen K, Guy RH, Petersson K. The potential of polymeric film-forming systems as sustained delivery platforms for topical drugs. Exp Opin Drug Delivery 2016;13:349-60.

4. Patel RP, Patel G, Patel H, Baria A. Formulation and evaluation of transdermal patch of aceclofenac. Res J Pharm Dosage Forms Tech 2009;1:108-15.

5. Nuha R, Abdul SM, Hajera H, Seema F. Simultaneous formulation, evaluation and estimation of controlled release of NSAID drug. Asian J Pharma Anal 2017;7:176-84.

6. Liu J, Xiao Y, Allen C. Polymer-drug compatibility: a guide to the development of delivery systems for the anticancer agent, ellipticine. J Pharm Sci 2004;93:132-43.

7. Li X, Zhang R, Liang R, Liu W, Wang C, Su Z, et al. Preparation and characterization of sustained-release rotigotine filmforming gel. Int J Pharm 2014;460:273-9.

8. Harish NM, Prabhu P, Charyulu RN, Gulzar MA, Subrahmanyam EVS. Formulation and evaluation of in situ gels containing clotrimazole for oral candidiasis. Ind J Pharm Sci 2009;71:421-7.

9. Arellano A, Santoyo S, Martín C, Ygartua P. Influence of propylene glycol and isopropyl myristate on the in vitro percutaneous penetration of diclofenac sodium from carbopol gels. Eur J Pharm Sci 1999;7:129-35.

10. Tas C, Ozkan Y, Savaser A, Baykara T. In vitro and ex vivo permeation studies of chlorpheniramine maleate gels prepared by carbomer derivatives. Drug Dev Indust Pharm 2004;30:637-47.

11. Patel J, Patel B, Banwait HS, Parmar K, Patel M. Formulation and evaluation of topical aceclofenac gel using different gelling agent. Int J Drug Dev Res 2011;3:156-64.

12. Singh V, Busheetti SS, Raju SA, Ahmad R, Singh M. In vitro and in vivo evaluation of stimuli sensitive hydrogel for ophthalmic drug delivery. Ind J Pharm Edu Res 2010;44:380-5.

13. Attia MA, Badawy HYE. Film-forming gel for treatment of oral mucositis: in vitro studies. Int J Drug Delivery 2010;2:314-21.

14. Hardainiyan SK, Kumar K, Nandy BC, Saxena R. Design, formulation and in vitro drug release from transdermal patches containing imipramine hydrochloride as model drug. Int J Pharm Pharm Sci 2017;9:220-5.

15. Tas C, Ozkan Y, Savaser A, Baykara T. In vitro and ex vivo permeation studies of chlorpheniramine maleate gels prepared by carbomer derivatives. Drug Dev Indust Pharm 2004;30:637-47.

16. Garg A, Aggarwal D, Garg S, Singla AK. Spreading of semisolid formulations. Pharm Tech; 2002. p. 84-105.

17. Bernkop SA, Dünnhaupt S. Eudragit-based drug delivery systems. Eur J Pharm Biopharm 2012;81:463-9.

18. Bhattarai N, Gunn J, Zhang M. Eudragit-based hydrogels for controlled, localized drug delivery. Adv Drug Delivery Rev 2010;62:83-99.

19. Chen Y, Wang M, Fang. Biomaterials as novel penetration enhancers for transdermal and dermal drug delivery systems. Drug Delivery 2013;20:199-209. 
20. Vij NN, Saudagar RB. Formulation, development and evaluation of film forming gel for prolonged dermal delivery of terbinafine hydrochloride. Int J Pharm Sci Res 2014;5:537-54.
21. Keerthana M, Shirisha S, Sahoo SK, Rao Y. Formulation and evaluation of bilayered felodipine transdermal patches: in vitro and ex vivo characterization. Asian J Pharm Clin Res 2021;14:106-11. 